\title{
Structural Studies on Molecular Interactions between Camel Peptidoglycan Recognition Protein, CPGRP-S, and Peptidoglycan Moieties $\mathrm{N}$-Acetylglucosamine and $\mathrm{N}$-Acetylmuramic Acid ${ }^{*[}$
}

Received for publication, November 7, 2011, and in revised form, May 7, 2012 Published, JBC Papers in Press, May 9, 2012, DOI 10.1074/jbc.M111.321307

Pradeep Sharma ${ }^{\ddagger 1}$, Shavait Yamini ${ }^{\ddagger}$, Divya Dube $^{\ddagger}$, Amar Singh $^{\S}$, Mau Sinha $^{\ddagger}$, Sharmistha Dey ${ }^{\ddagger}$, Dipendra K. Mitra $^{\S}$, Punit Kaur ${ }^{\ddagger}$, Sujata Sharma ${ }^{\ddagger}$, and Tej P. Singh ${ }^{\ddagger 2}$

From the ${ }^{\ddagger}$ Department of Biophysics and the ${ }^{\S}$ Department of Transplantation Immunology and Immunogenetics, All India Institute of Medical Sciences, New Delhi 110029, India

Background: PGRP-S is an innate immunity protein that protects hosts from invading microbes.

Results: CPGRP-S forms linear polymers with alternating A-B and C-D contacts, and both GlcNAc and MurNAc bind at the same subsite.

Conclusion: The mode of binding of camel PGRP-S is different from other PGRPs.

Significance: The better antibacterial properties of camel PGRP-S can be exploited for therapeutic applications.

Peptidoglycan (PGN) consists of repeating units of $\mathrm{N}$-acetylglucosamine (GlcNAc) and $N$-acetylmuramic acid (MurNAc), which are cross-linked by short peptides. It is well known that PGN forms a major cell wall component of bacteria making it an important ligand for the recognition by peptidoglycan recognition proteins (PGRPs) of the host. The binding studies showed that PGN, GlcNAc, and MurNAc bind to camel PGRP-S (CPGRP-S) with affinities corresponding to dissociation constants of $1.3 \times 10^{-9}, 2.6 \times 10^{-7}$, and $1.8 \times 10^{-7} \mathrm{M}$, respectively. The crystal structure determinations of the complexes of CPGRP-S with GlcNAc and MurNAc showed that the structures consist of four crystallographically independent molecules, $\mathrm{A}$, $\mathrm{B}, \mathrm{C}$, and $\mathrm{D}$, in the asymmetric unit that exists as A-B and C-D units of two neighboring linear polymers. The structure determinations showed that compounds GlcNAc and MurNAc bound to CPGRP-S at the same subsite in molecule C. Both GlcNAc and MurNAc form several hydrogen bonds and extensive hydrophobic interactions with protein atoms, indicating the specific nature of their bindings. Flow cytometric studies showed that PGN enhanced the secretions of TNF- $\alpha$ and IL-6 from human peripheral blood mononuclear cells. The introduction of CPGRP-S to the PGN-challenged cultured peripheral blood mononuclear cells reduced the expressions of proinflammatory cytokines, TNF- $\alpha$ and IL- 6 . This showed that CPGRP-S inhibited PGN-induced production of proinflammatory cyto-

* This work was supported by the Department of Science and Technology and Department of Biotechnology, Ministry of Science and Technology, Government of India (New Delhi).

5 This article contains supplemental Table S1 and Figs. S1-S6.

The atomic coordinates and structure factors (codes $4 E B T$ and $4 E B S$ ) have been deposited in the Protein Data Bank, Research Collaboratory for Structural Bioinformatics, Rutgers University, New Brunswick, NJ (http://www.rcsb.org/).

${ }^{1}$ Recipient of a Department of Science and Technology Innovation in Science Pursuit for Inspired Research (INSPIRE) Faculty award.

${ }^{2}$ Recipient of a Department of Biotechnology Distinguished Biotechnology Research Professorship grant. To whom correspondence should be addressed: Dept. of Biophysics, All India Institute of Medical Sciences, Ansari Nagar, New Delhi 110 029, India. Tel.: 91-11-2658-8931; Fax: 91-112658-8663; E-mail: tpsingh.aiims@gmail.com. kines and down-regulated macrophage-mediated inflammation, indicating its potential applications as an antibacterial agent.

The first line of defense in the host against invading microorganisms is provided by its innate immune system, which contains several proteins including peptidoglycan recognition proteins (PGRPs). ${ }^{3}$ PGRPs recognize conserved motifs that are present on the bacterial cell surface and are known as pathogen-associated molecular patterns (PAMPs) (1). Similar patterns are absent in the mammalian systems (2). One of the most commonly occurring PAMPs is peptidoglycan (PGN) molecule, which is a polymer of $\beta(1-4) N$-acetylglucosamine (GlcNAc) and $N$-acetylmuramic acid (MurNAc) with all lactyl groups of MurNAc substituted with stem peptides containing alternating $\mathrm{L}^{-}$and D-amino acids (3). The peptide chain from one strand is either directly cross-linked to the neighboring chain of polysaccharides or through a short peptide. The polysaccharide strands generally maintain a constant structure in various bacteria. In contrast, the sequences and conformations of cross-linking peptides may vary considerably. It is well known that in Gram-negative bacteria, the third residue is meso-diaminopimelic acid, whereas in Gram-positive bacteria, it is L-lysine. To characterize the binding properties of CPGRP-S with PGN and various other PAMPs, we have determined the crystal structures of three complexes of CPGRP-S with lipopolysaccharide (LPS (4)), lipoteichoic acid (LTA (4)), and muramyl dipeptide (MDP (5)). The structures of a few

\footnotetext{
${ }^{3}$ The abbreviations used are: PGRP, peptidoglycan recognition protein; CPGRP-S, camel PGRP-S; hPGRP; human PGRP; DPGRP, Drosophila PGRP; PAMP, pathogen-associated molecular pattern; LTA, lipoteichoic acid; MDP, $N$-acetyl muramyl-alanyl-isoglutamine; PGN1, peptidoglycan from B. subtilis; PGN2, peptidoglycan from E. coli; PGN3, peptidoglycan from Escherichia coli K12; MTP, N-acetylmuramyl-alanyl-glutamic acid-lys; EDC, 1-ethyl-3-(3- $N, N$-dimethylaminopropyl)carbodiimide; FMO, fluorescence minus one; DAP, di-amino pimelic acid.
} 
other complexes of different PGRPs such as human PGRP-I $\alpha$ (HPGRP-I $\alpha$ ) with muramyl tripeptide (MTP (6)), muramyl pentapeptide ( $N$-acetylmuramyl-alanyl-Glu-Lys-Ala-Ala (7)), and HPGRP-I $\beta$ with muramyl pentapeptide ( $N$-acetyl-D-glucosamine-methyl-2-(acetylamino)-3-O-[(1r)-1-carboxyethyl]2 -deoxy- $\beta$-D-glucopyranoside-Ala-Glu-Lys-Ala-Ala (8)) as well as with Drosophila PGRP-LCa (DPGRP-LCa) and Drosophila PGRP-LCx (DPGRP-LCx) with tracheal cytotoxin (9) have also been reported.

The presence of PGN in virtually all bacterial cell walls and its absence in mammalian cell walls makes it an important target for the recognition by PGRPs $(1,10-17,19,20)$. It may be noted that PGRPs are part of innate immune system in mammals and show distinct specificities toward PGNs (15). In view of this, it is important to understand the role of PGRPs, and to achieve this, it is essential to determine the modes of binding of PGNs to PGRPs through binding studies and crystallographic investigations. On the basis of their sizes and biological actions, the mammalian PGRPs are broadly divided into two types: (i) PGRPs as recognition molecules such as PGRP-short (PGRP-S) and PGRP-intermediate (PGRP-I $\alpha$ and PGRP-I $\beta$ ) and (ii) the catalytic molecule such as PGRP-long (PGRP-L). In one of the recent reports, the peptide component of PGN was suggested to be a more critical factor than its glycan moieties in the binding to PGRPs (21). It may be mentioned here that the two glycan moieties GlcNAc and MurNAc are regular features of various PAMPs, whereas the sequences of cross-linking peptides often vary (11). Therefore, to determine the significance of the presence of GlcNAc and MurNAc in PGN and their roles in the recognition of PGN by PGRPs, we have carried out detailed binding studies of PGN, GlcNAc, and MurNAc in solution and determined the crystal structures of the complexes of CPGRP-S with (i) GlcNAc and (ii) MurNAc. The binding constants of CPGRP-S with PGN, GlcNAc, and MurNAc have been estimated using surface plasmon resonance and fluorescence spectroscopic techniques. The significance of molecular interactions have been analyzed by determining the effects of CPGRP-S on the expression levels of proinflammatory cytokines, TNF- $\alpha$ and IL-6, in the PGN-challenged human peripheral blood mononuclear cell cultures using flow cytometry.

\section{MATERIALS AND METHODS}

Purification-Fresh samples of camel milk were obtained from the National Research Centre on Camels, Bikaner, India. The skimmed milk was diluted twice with $50 \mathrm{~mm}$ Tris- $\mathrm{HCl}, \mathrm{pH}$ 8.0. The cation exchanger CM-Sephadex (C-50) pre-equilibrated with $50 \mathrm{~mm}$ Tris- $\mathrm{HCl}, \mathrm{pH} 8.0$, at a concentration of 7 $\mathrm{g} /$ liter was added to the diluted samples and stirred slowly for $1 \mathrm{~h}$ with a glass rod. The gel was allowed to settle for half an hour after which the solution was decanted. The gel was washed with an excess of $50 \mathrm{~mm}$ Tris- $\mathrm{HCl}, \mathrm{pH}$ 8.0. It was packed in a column $(25 \times 2.5 \mathrm{~cm})$ and washed with same buffer until the absorbance reduced to 0.05 at $280 \mathrm{~nm}$. After this, the bound basic proteins were eluted with $0.5 \mathrm{M} \mathrm{NaCl}$ in $50 \mathrm{~mm}$ Tris- $\mathrm{HCl}, \mathrm{pH}$ 8.0, and desalted by dialyzing the sample against triple distilled water. The desalted fraction was again passed through a CMSephadex $(\mathrm{C}-50)$ column $(10 \times 2.5 \mathrm{~cm})$ that was pre-equilibrated with $50 \mathrm{~mm}$ Tris- $\mathrm{HCl}, \mathrm{pH} 8.0$, and eluted with $0.05-0.5$
$\mathrm{M} \mathrm{NaCl}$ in the same buffer. The eluted fractions were examined on the sodium dodecyl sulfate polyacrylamide gel electrophoresis (SDS-PAGE). The fractions corresponding to a molecular mass of $20 \mathrm{kDa}$ were pooled. The pooled fractions were concentrated with Amicon ultrafiltration cell. The concentrated protein was passed through Sephadex G-100 column $(100 \times 2 \mathrm{~cm})$ using $50 \mathrm{~mm}$ Tris- $\mathrm{HCl}, \mathrm{pH}$ 8.0. Two peaks with one peak in the void volume were observed when the fractions were read at a wavelength of $280 \mathrm{~nm}$. These were examined using SDS-PAGE and matrix assisted laser desorption/ionization- time of flight (MALDI-TOF). In SDS-PAGE both the peaks corresponded to the molecular mass of $20 \mathrm{kDa}$ of PGRP-S. In MALDI-TOF, a single peak of molecular mass of $20 \mathrm{kDa}$ was observed.

PGN Binding Assay-Lys-type PGN from Bacillus subtilis (PGN1) and DAP-type PGN from Escherichia coli (PGN2) were obtained from Sigma. PGN binding assay was carried out according to the procedure of Takehana et al. (22). The purified CPGRP-S $(0.5 \mu \mathrm{g})$ was incubated with $0.32 \mathrm{mg}$ of insoluble Lys-type PGN or DAP-type PGN. Unbound protein isolated from the soluble fraction and bound protein recovered after washing the PGN with Tris-maleate buffer containing $1 \mathrm{M} \mathrm{NaCl}$ and $1 \mathrm{M} \mathrm{NaCl}$ plus $0.2 \%$ Tween 20 were examined using SDS-PAGE.

Surface Plasmon Resonance Analysis of CPGRP-PGN Interactions - The biospecific interaction analysis was performed using BIAcore 2000 biosensor system (Biacore Inc., Uppsala, Sweden). The CM-5 research grade sensor chip, HBS-EP buffer (pH 7.4, 0.01 м HEPES, 150 m M NaCl, 3 mm EDTA, 0.005\% P20) and immobilization reagents (1-ethyl-3-(3-N,N-dimethylaminopropyl) carbodiimide (EDC), $N$-hydroxysuccinimide, and ethanolamine) were obtained from BIAcore, and phosphate-buffered saline was purchased from Sigma. All solutions were filtered using a $0.22-\mu \mathrm{m}$ polyethersulfone membrane syringe filter and degassed before use. CPGRP-S was covalently immobilized by a standard amine coupling procedure using the amine coupling kit supplied by the manufacturer. A fixed flow rate of $10 \mu \mathrm{l} / \mathrm{min}$ was used throughout the immobilization procedure with HBS-EP as the running buffer. The surface was activated using $70 \mu \mathrm{l}$ of freshly mixed 1:1 $100 \mathrm{~mm} N$-hydroxysuccinimide and $391 \mathrm{~mm}$ EDC for $7 \mathrm{~min}$. Upon activation, a 60 $\mu \mathrm{g} / \mathrm{ml}$ solution of CPGRP-S in $10 \mathrm{~mm} \mathrm{NaOAc}, \mathrm{pH} 4.5$, was injected for $8 \mathrm{~min}$. The remaining active esters on the surface were quenched using $70 \mu \mathrm{l}$ of $1.0 \mathrm{M}$ ethanolamine, $\mathrm{pH} 8.5$, for 7 min. A ligand density of $4935 \mathrm{RU}$ was achieved. Three different concentrations of analytes PGN, GlcNAc, and MurNAc were passed over immobilized CPGRP-S at a flow rate of $10 \mu \mathrm{l} / \mathrm{min}$ in each case. PGN used in this experiment was PGN-ECndss ultrapure, which was soluble sonicated peptidoglycan from E. coli K12 (PGN3) obtained from InvivoGen, San Diego, CA. The regeneration of the protein surface from bound analytes was done by injecting $10 \mathrm{~mm} \mathrm{NaOH}, \mathrm{pH} 11.4$, at a flow rate of 30 $\mu \mathrm{l} / \mathrm{min}$. The association $\left(K_{\text {on }}\right)$ and dissociation $\left(K_{\text {off }}\right)$ rate constants for the bindings of analytes to CPGRP-S were calculated, and the values of dissociation constants $\left(K_{d}\right)$ were determined by the mass action relation $K_{d}=K_{\text {off }} / K_{\text {on }}$ using BIA evaluation 3.0 software provided by the manufacturer.

Fluorescence Spectroscopy - The fluorescence emission spectra were recorded on spectrofluorimeter, FP-6200 (Shimadzu, 
Kyoto, Japan) using a 1-cm quartz cell in the wavelength range of 300-450 $\mathrm{nm}$ using an excitation wavelength of $280 \mathrm{~nm}$ at $298 \mathrm{~K}$. The excitation and emission slits were set at the same value of $5 \mathrm{~nm}$ with the scanning speed of $125 \mathrm{~nm} / \mathrm{min}$. The final concentrations of PGN, GlcNAc, and MurNAc used for the recording of emission spectra were $5,10,15,20$, and $25 \mu \mathrm{l}$ in 10 mM HEPES buffer, $\mathrm{pH}$ 8.0, from the stock solutions of ligands prepared at concentrations of $1 \times 10^{-7} \mathrm{M}$ in the same buffer, whereas CPGRP-S concentration was kept fixed at $1 \times 10^{-9} \mathrm{M}$ for all the measurements. The fluorescence effects of all the three ligands were subtracted from the spectra of CPGRP-S in complexes, and the binding were obtained.

Antibacterial Activity Assay-The importance of proteinPGN interactions in the antimicrobial activity of CPGRP-S were assessed using suspension assays. The $E$. coli bacterial cells were grown to mid-log phase in $1 \times \mathrm{TSB}(3 \% \mathrm{w} / \mathrm{v}$; contains $0.5 \%$ $\mathrm{NaCl}(\sim 86 \mathrm{~mm})$ at $37^{\circ} \mathrm{C}$. The $10-\mu$ l aliquots of cells were added to $2 \mathrm{ml}$ of TSB. The purified CPGRP-S was added to a final concentration of $25 \mu \mathrm{g} / \mathrm{ml}$ either alone or supplemented with $100 \mu \mathrm{g} / \mathrm{ml}$ Staphylococcus aureus PGN or E. coli LPS (Sigma). The tubes were shaken at $300 \mathrm{rpm}$ for $5 \mathrm{~h}$, and bacterial density was monitored by measurements of optical density at $600 \mathrm{~nm}$ at 1-h intervals. To minimize the effect of bacterial aggregation on optical density, the cell suspensions were stirred for $1 \mathrm{~min}$ before each measurement.

Isolation of Peripheral Blood Mononuclear Cells from Peripheral Blood-In this study, a total of 7 peripheral blood samples from healthy adults were analyzed. All peripheral blood samples were collected in heparinized vials and immediately processed for the analysis of cytokine production. All samples were obtained with the approval of the local ethics committee after informed consent had been given by the donor. The mononuclear cells were isolated from heparinized blood by Ficoll Hypaque gradient centrifugation and suspended in complete RPMI 1640 (Caisson Laboratories, Logan, UT) supplemented with $2 \mathrm{~mm}$ glutamine, 100 units $/ \mathrm{ml}$ penicillin, $100 \mu \mathrm{g} / \mathrm{ml}$ streptomycin, and $10 \%$ heat-inactivated fetal calf serum. The viability of cells was measured by trypan blue dye exclusion test and was greater than $97 \%$. These cells were used for in vitro culture.

Cell Culture and Flow Cytometry-The in vitro stimulation of freshly isolated peripheral blood mononuclear cells was performed for measuring proinflammatory cytokine production with PGN. These cells were cultured in three different experimental conditions: media alone, $10 \mu \mathrm{g} / \mathrm{ml} \mathrm{PGN,} \mathrm{and} 10 \mu \mathrm{g} / \mathrm{ml}$ PGN $+5 \mu \mathrm{g} / \mathrm{ml}$ PGRP in presence of $10 \mu \mathrm{g} / \mathrm{ml}$ of brefeldin, a Golgi transport inhibitor (Sigma). After $24 \mathrm{~h}$, culture cells were washed and surface-stained with anti-CD3 (BD Biosciences) followed by intracellular staining for TNF- $\alpha$ and IL-6 (BD Bioscience). The stained cells were run in BD FACSCalibur (BD Biosciences) and subsequently analyzed by FlowJo software (Tree Star Inc., Ashland, OR). Statistical significance of results was determined using Sigma Plot and Prism 5 software (GraphPad, La Jolla, CA).

Measurement of Molecular Size Using Dynamic Light Scattering-Light scattering is extremely sensitive for determining even small amounts of aggregates. Protein samples were prepared in distilled water at various concentrations $(2,1$, and $0.5 \mathrm{mg} / \mathrm{ml}$ ) for which hydrodynamic radii were obtained. To evaluate the effects of salt on aggregating behavior of CPGRP-S, various concentrations of $\mathrm{NaCl}(0.5,1,2,2.5$, and $5.0 \mathrm{M})$ were added to the protein solution. To assess the influence of organic solvents, these measurements were also made in the presence of 5,10 , and $20 \%$ ethanol. In all these experiments, the protein concentration was maintained at $1 \mathrm{mg} / \mathrm{ml}$.

Transmission Electron Microscopy-Protein samples were dissolved in distilled water at concentration of $1 \mathrm{mg} / \mathrm{ml}$. The samples were agitated gently before being spotted on a 400mesh carbon-coated EM grid for 2 min and fixed with 4\% paraformaldehyde for $30 \mathrm{~s}$. Micrographs were recorded using transmission electron microscope (FEI Tecnai $20 \mathrm{~S}$ TWIN, The Netherlands).

Crystallization-Freshly purified samples of protein were dissolved in $50 \mathrm{~mm}$ Tris- $\mathrm{HCl}, \mathrm{pH} 8.0$, containing $10 \mathrm{~mm}$ GlcNAc and $10 \mathrm{~mm}$ MurNAc in separate vials to a concentration of $15 \mathrm{mg} / \mathrm{ml}$. The $3 \mu \mathrm{l}$ of above solutions were mixed with equal volumes of reservoir solutions of $10 \%$ polyethylene glycol 3350 (PEG-3350) containing $0.2 \mathrm{~m}$ sodium potassium tartrate. The 6- $\mu$ l drops were set up using a hanging drop vapor diffusion method against $2 \mathrm{ml}$ of reservoir solution. The crystals from these two samples grew to average dimensions of $0.4 \times$ $0.3 \times 0.3 \mathrm{~mm}^{3}$ and $0.5 \times 0.3 \times 0.3 \mathrm{~mm}^{3}$, respectively, in about 3 weeks. The freshly grown crystals of CPGRP-S complexes with GlcNAc and MurNAc were used for data collection.

Detection of GlcNAc and MurNAc in Crystals-To confirm the presence of GlcNAc and MurNAc molecules in the crystals of two samples, the crystals of both preparations of CPGRP-S with GlcNAc and MurNAc were used. Initially, the crystals were washed thoroughly with distilled water to remove unbound material from the surface and then these were allowed to dissolve until a clear solution was obtained. Both solutions were incubated with $1 \mathrm{M} \mathrm{NaCl}$ for $1 \mathrm{~h}$ and then ultrafiltered using a membrane with a molecular mass cutoff of $3 \mathrm{kDa}$. The concentration of GlcNAc in the filtrate was estimated using the method of Reissig et al. (23) with a slight modification. To the sample, contained in a volume of $0.5 \mathrm{ml}$ in a $100 \times 13-\mathrm{mm}$ test tube, $>0.1 \mathrm{ml}$ of potassium tetraborate was added. The tubes were heated in a vigorously boiling water bath for exactly $3 \mathrm{~min}$ and cooled in tap water. $3 \mathrm{ml}$ of $p$-dimethyl-aminobenzaldehyde reagent was added. Immediately after mixing, the tubes were placed in a water bath at $38^{\circ} \mathrm{C}$. After $20 \mathrm{~min}$ the tubes were cooled in tap water and read out at $585 \mathrm{~nm}$. At $38^{\circ} \mathrm{C}$, full color developed in $20 \mathrm{~min}$. In another experiment, the qualitative detection of MurNAc was carried out using the method of Hoijer (24). The samples were hydrolyzed by heating for $2 \mathrm{~h}$ at $90{ }^{\circ} \mathrm{C}$ with an equal volume of $5 \mathrm{M} \mathrm{H}_{2} \mathrm{SO}_{4}$ and then neutralized with $10 \mathrm{M} \mathrm{NaOH}$. Hydrolyzed and unhydrolyzed samples (100 $\mu \mathrm{l}$ each) were incubated with $50 \mu \mathrm{l}$ of $1 \mathrm{M} \mathrm{NaOH}$ at $36^{\circ} \mathrm{C}$ for $30 \mathrm{~min}$. After the addition of $1 \mathrm{ml}$ of $18.8 \mathrm{M} \mathrm{H}_{2} \mathrm{SO}_{4}$ (concentrated), samples were heated for $3.5 \mathrm{~min}$ at $100{ }^{\circ} \mathrm{C}$, rapidly cooled in ice, and then mixed with $10 \mathrm{ml}$ of $0.16 \mathrm{M} \mathrm{CuSO}_{4} \cdot 5 \mathrm{H}_{2} \mathrm{O}$ in $\mathrm{H}_{2} \mathrm{O}$ and $20 \mu$ l of $0.09 \mathrm{M} p$-hydroxydiphenyl in ethanol. The blue color developed to a maximum in $30 \mathrm{~min}$ at $30{ }^{\circ} \mathrm{C}$ and was read at $570 \mathrm{~nm}$.

$X$-ray Intensity Data Collection and Processing-The freshly grown crystals of two complexes of CPGRP-S with GlcNAc and MurNAc were stabilized by adding 30\% PEG-3350 and $0.2 \mathrm{M}$ 
TABLE 1

Data collection and refinement statistics for the structures of the complexes of CPGRP-S with GIcNAc and MurNAc

The values in parentheses correspond to the values in the highest resolution shell. r.m.s.d., root mean square deviation.

\begin{tabular}{|c|c|c|}
\hline & $\begin{array}{c}\text { CPGRP-S + } \\
\text { GIcNAc }\end{array}$ & $\begin{array}{c}\text { CPGRP-S + } \\
\text { MurNAc }\end{array}$ \\
\hline PDB ID & 4EBT & 4EBS \\
\hline Space group & $\mathrm{I} 222$ & $\mathrm{I} 222$ \\
\hline \multicolumn{3}{|l|}{ Unit cell dimensions } \\
\hline$a(\AA)$ & 90.5 & 88.2 \\
\hline$b(\AA)$ & 102.1 & 101.5 \\
\hline$c(\AA)$ & 164.1 & 163.0 \\
\hline Number of molecules in the unit cell & 32 & 32 \\
\hline$V_{m}\left(\AA^{3} / \mathrm{Da}\right)$ & 2.49 & 2.40 \\
\hline Solvent content (\%) & 47.0 & 48.7 \\
\hline Resolution range $(\AA)$ & $20.0-2.60$ & $20.0-2.60$ \\
\hline Total number of measured reflections & 180,548 & 162,516 \\
\hline Number of unique reflections & 22,283 & 22,829 \\
\hline$R_{\mathrm{sm}}{ }^{a}(\%)$ & $10.4(43.1)$ & $9.2(32.8)$ \\
\hline$I / \sigma(I)$ & $7.7(2.0)$ & $11.0(2.0)$ \\
\hline Overall completeness of data (\%) & $94.1(96.6)$ & $99.8(100.0)$ \\
\hline$R_{\text {cryst }}^{b}(\%)$ & 19.6 & 22.3 \\
\hline$\left.R_{\text {fryet }}^{\text {cryst }} \%\right)$ & 21.4 & 24.6 \\
\hline Protein atoms & 5,348 & 5,348 \\
\hline Water oxygen atoms & 319 & 338 \\
\hline Atoms of glycerol & & 6 \\
\hline Atoms of tartrate & 10 & 10 \\
\hline Atoms of ligands & 15 & 20 \\
\hline $\begin{array}{l}\text { r.m.s.d. in bond lengths }(\AA) \\
\text { (n) }\end{array}$ & 0.009 & 0.01 \\
\hline r.m.s.d. in bond angles $\left(^{\circ}\right)$ & 2.0 & 1.7 \\
\hline r.m.s.d. in torsion angles $\left({ }^{\circ}\right)$ & 24.3 & 24.1 \\
\hline Wilson's B-factor & 34.1 & 46.4 \\
\hline Mean B-factor for main chain atoms $\left(\AA^{2}\right)$ & 32.0 & 48.4 \\
\hline Mean B-factor for side chain atoms $\left(\AA^{2}\right)$ & 33.8 & 50.0 \\
\hline Mean B-factor for water oxygen atoms $(\AA)$ & 44.2 & 52.7 \\
\hline Mean B-factor for all atoms $\left(\AA^{2}\right)$ & 32.9 & 49.4 \\
\hline Ramachandran $\varphi, \psi$ map & & \\
\hline $\begin{array}{l}\text { Residues in the most favored } \\
\text { regions (\%) }\end{array}$ & 91.2 & 91.3 \\
\hline Residues in the additionally allowed regions (\%) & 8.8 & 8.7 \\
\hline
\end{tabular}

sodium potassium tartrate for data collection at low temperatures. The crystals were mounted in nylon loops and flash-frozen in the liquid nitrogen at $100 \mathrm{~K}$. Two $\mathrm{x}$-ray intensity data sets were collected using one crystal each of dimensions of $0.41 \times$ $0.32 \times 0.28$ and $0.45 \times 0.36 \times 0.28 \mathrm{~mm}^{3}$ for the complexes of CPGRP-S with GlcNAc and MurNAc, respectively. The DBTsponsored MX beamline, BM14 at ESRF, Grenoble, France with a wavelength of $\lambda=0.98 \AA$ on $165 \mathrm{~mm}$ MAR CCD detector was used for sets of data collection. The data were processed with AUTOMAR and SCALEPACK from HKL package (25). The overall completeness of data for the crystals of the complexes of CPGRP-S with GlcNAc was $94.1 \%$ to 2.60 A resolution and with MurNAc was $99.8 \%$ to $2.60 \AA$ resolution. The results of data collection and processing on both crystals are given in Table 1.

Structure Determination and Refinement-Structures of the complexes of CPGRP-S with GlcNAc and MurNAc were determined using molecular replacement method (26). The coordinates of the unbound CPGRP-S (PDB ID 3C2X, 27) were used as the model. The structures were refined using program REFMAC 5.5 (28). The structures were gradually improved by repeated manual model buildings using program $\mathrm{O}(29)$ and Coot (30). The tight main-chain and side-chain non-crystallographic symmetry restraints between four crystallographically independent molecules $\mathrm{A}, \mathrm{B}, \mathrm{C}$, and $\mathrm{D}$ were used in the refinement. The electron density maps $\left(2 F_{o}-F_{c}\right)$ and $\left(F_{o}-F_{c}\right)$ were calculated for adjusting the protein chains in the electron densities. After several rounds of model rebuilding and intermittent cycles of refinements, $R_{\text {cryst }}$ factors for the two structures containing GlcNAc and MurNAc dropped to 0.282 and 0.308 , respectively. The omit maps were calculated by deleting short segments one by one covering the complete protein chain. The positions of side chains of amino acid residues were adjusted manually. The group temperature factor B refinements were used to further improve the model. These steps further reduced the values of $R_{\text {cryst }}$ factors to 25.3 and $27.8 \%$ for structures GlcNAc and MurNAc, respectively. The Fourier $\left(2 F_{o}-F_{c}\right)$ and difference Fourier $\left(F_{o}-F_{c}\right)$ maps computed at this stage showed the presence of significant non-protein electron densities at the ligand binding cleft in molecule $\mathrm{C}$. It may be recalled that the ligand binding site in CPGRP-S is located in molecule $\mathrm{C}$ at the C-D contact $(4,5)$. The ligands GlcNAc and MurNAc were fitted well into the electron densities (Fig. 1). However, their occupancies were optimized at 0.7. The atoms of both ligands were added to the respective models in the further cycles of refinements with isotropic B-factors. After this, the coordinates of water oxygen atoms were also added to the model for refinements in the subsequent cycles. The values of $R_{\text {cryst }} / R_{\text {free }}$ factors converged finally to $0.196 / 0.214$ and $0.223 /$ 0.246 , respectively. The final models of the two complexes of CPGRP-S with GlcNAc and MurNAc comprised of four crystallographically independent protein molecules A, B, C and D, each having residues from 1 to 171 and a bound GlcNAc molecule in Fig. $1 a$ and a bound MurNAc molecule in structure Fig. $1 b$. It may be noted that the electron densities for the first five $\mathrm{N}$-terminal residues in all the four protein molecules of the two structures were relatively weak, indicating that the $\mathrm{N}$-terminal fragment of CPGRP-S was flexible. However, the directions of the protein chains could be followed unambiguously (supplemental Fig. S1). The positions of 319 and 338 water oxygen atoms in the complexes of CPGRP-S with GlcNAc and MurNAc, respectively were also determined. The data collection and refinement statistics are listed in Table 1.

\section{RESULTS}

PGN Binding Analysis-Even after repeated washings, the CPGRP-S was retained by both Lys-type PGN from S. aureus and DAP-type PGN from E. coli. Although it is stated that PGRPs bind either Lys-type PGN or DAP-type PGN, the present results indicated that CPGRP-S has affinity for both Lystype as well as for DAP-type PGNs. Even though the sensitivity of the current assay is not sufficiently high to quantitate the differential bindings of CPGRP-S to these PGNs, it is clearly observed that CPGRP-S binds to both compounds equally well, although it shows a slightly higher affinity for DAP-type PGNs (Fig. 2).

Antibacterial Activity - The effect of PGN was examined on the inhibition of antimicrobial activity of CPGRP-S (Fig. 3). The effect of LPS on the inhibition of antimicrobial activity of CPGRP-S was also plotted as a reference for comparison. The inclusion of excess S. aureus PGN $(100 \mu \mathrm{g} / \mathrm{ml})$ or E. coli LPS $(100 \mu \mathrm{g} / \mathrm{ml})$ completely blocked the CPGRP-S $(25 \mu \mathrm{g} / \mathrm{ml})$-mediated growth inhibition of S. aureus. Neither S. aureus PGN nor E. coli LPS affected growth in the absence of CPGRP-S. 


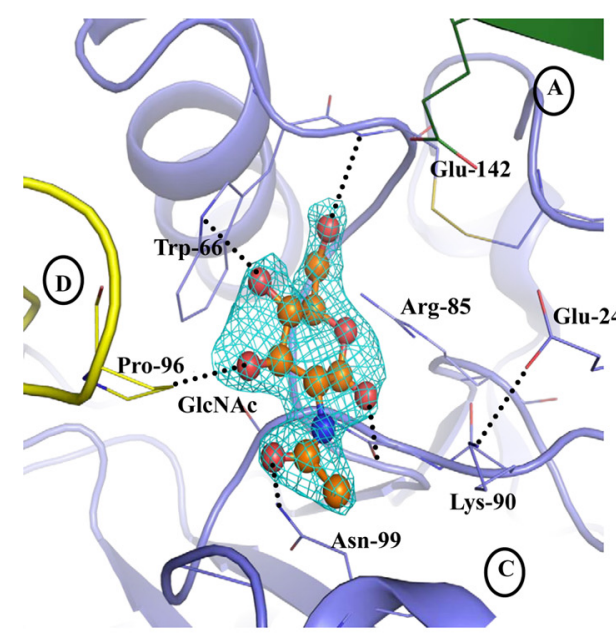

(a)



(b)

FIGURE 1. GIcNAc ( $a$ ) and MurNAc $(\boldsymbol{b})$ bound to CPGRP-S at the same subsite in the protein. The difference electron density maps $\left(F_{o}-F_{c}\right)$ calculated at $2.5 \sigma$ for GICNAc $(a)$ and MurNAc $(b)$ are shown. The dotted lines indicate hydrogen bonds.

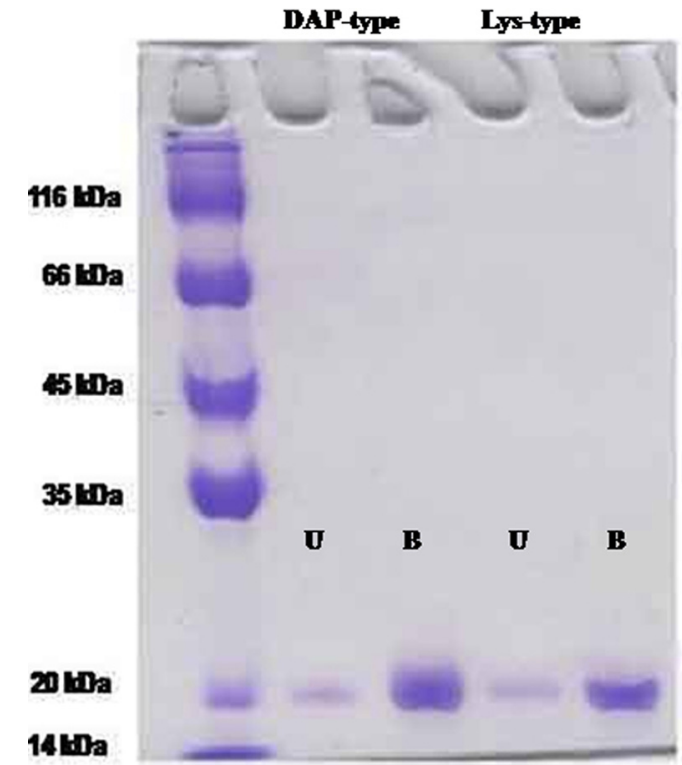

FIGURE 2. CPGRP-S binds to Lys-type and DAP-type PGNs. Purified CPGRP-S $(0.5 \mu \mathrm{g})$ was incubated with insoluble Lys-type or DAP-type PGN, and the bound protein on the insoluble PGN was separated from unbound protein as described under "Materials and Methods." Unbound protein (lane $U$ ) and bound protein (lane $B$ ) were analyzed by SDS-PAGE. Molecular markers are indicated on the left.

These results indicate that CPGRP-S inhibits the growth of bacteria presumably by the mechanism that includes the binding of bacterial cell wall components, PGN and LPS to the protein.

Surface Plasmon Resonance Spectroscopy - The binding experiments of CPGRP-S were carried out with PGN, GlcNAc, and MurNAc using real time surface plasmon resonance spectroscopy. The surface plasmon resonance sensograms showing the association and dissociation curves for PGN, GlcNAc, and MurNAc with the immobilized CPGRP-S are given in supplemental Fig. S2. The global fitting of the primary data to a Langmuir 1:1 association model using the BIA evaluation 3.0 software package provided the values of the dissociation constants ( $K_{d}$ values) of $1.6 \times 10^{-9}, 2.6 \times 10^{-7}$, and $1.8 \times 10^{-7} \mathrm{M}$ for the bindings of PGN, GlcNAc, and MurNAc respectively. These

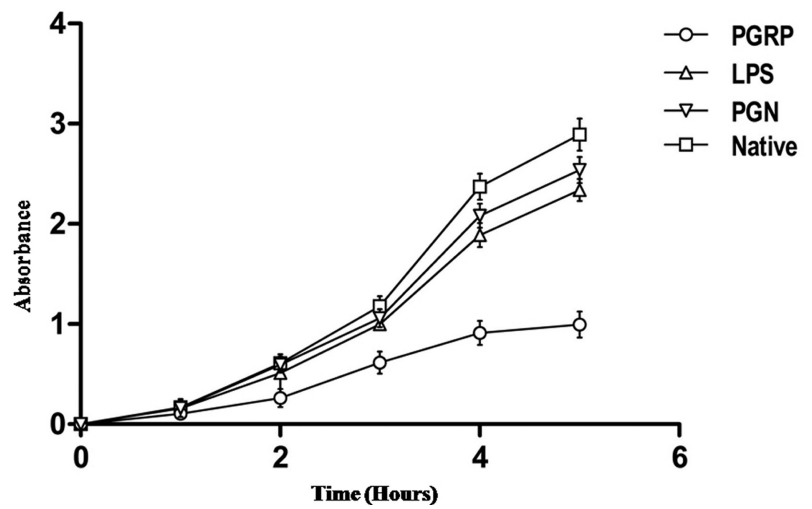

FIGURE 3. The antibacterial assay. Bacteria were incubated in $1 \times$ TSB $(3 \%$ $\mathrm{w} / \mathrm{v})$ with $25 \mu \mathrm{g} / \mathrm{ml}$ CPGRP-S either alone $(\bigcirc)$ or supplemented with 100 $\mu \mathrm{g} / \mathrm{ml} \mathrm{PGN}(\nabla), 100 \mu \mathrm{g} / \mathrm{ml}$ LPS $(\triangle)$, or no additives $(\square)$. The bacterial density was monitored by the measurement of optical density at $600 \mathrm{~nm}$ at 1-h intervals. For every measurement experiments were repeated six times. The data represent the mean \pm S.D. These values were estimated for each experiment, which was repeated six times. The values of optical density varied from 0.1 to 2.9, whereas the values of S.D. varied from 0.02 to 0.09 .

values indicate that CPGRP-S binds to GlcNAc and MurNAc with similar affinities.

Interactions of PGN, GlcNAc, and MurNAc with CPGRP-S Using Fluorescence Spectroscopy-Fluorescence emission spectroscopy was used to determine the binding constants of PGN, GlcNAc, and MurNAc. The emission fluorescence effects of CPGRP-S are contributed by at least four tryptophan amino acid residues. As seen from supplemental Fig. S3, the fluorescence emissions of CPGRP-S are obtained at $352 \mathrm{~nm}$. The different concentrations of PGN, GlcNAc, and MurNAc were used to study the interaction with CPGRP-S. Our results showed that with five increasing concentrations of these ligands $(5,10,15,20$, and $25 \mu \mathrm{l}$ in $10 \mathrm{~mm}$ HEPES, pH 8.0, from stock solutions of ligands prepared at $1 \times 10^{-7} \mathrm{M}$ in the same buffer) and a fixed concentration of CPGRP-S $\left(1 \times 10^{-9} \mathrm{M}\right)$, the maximum fluorescence (352 nm) of CPGRP-S was quenched upon binding of PGN, GlcNAc, and MurNAc. This indicates that bindings of PGN, GlcNAc, and MurNAc to CPGRP-S cause changes in the microenvironment of CPGRP-S that result in the formations of CPGRP-S complexes with PGN, GlcNAc, 
(a)

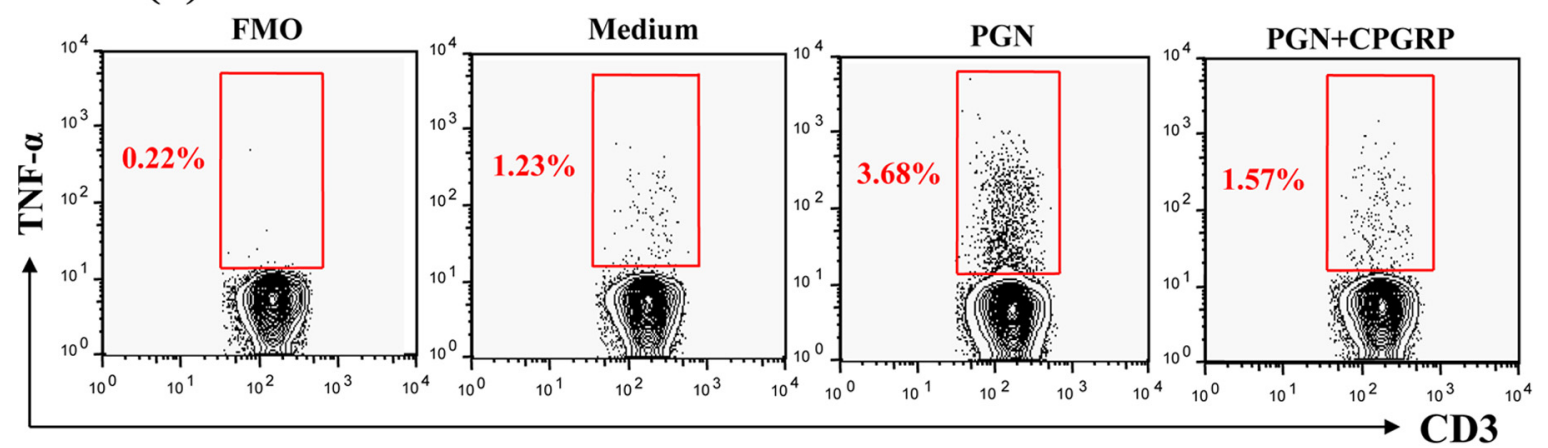

Gated on $\mathrm{CD3}^{+} \mathrm{T}$ cells

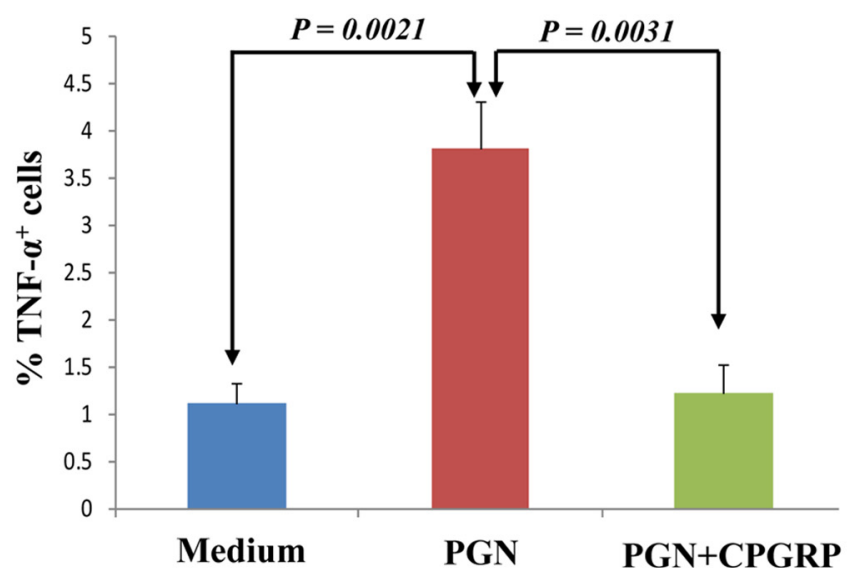

(b)
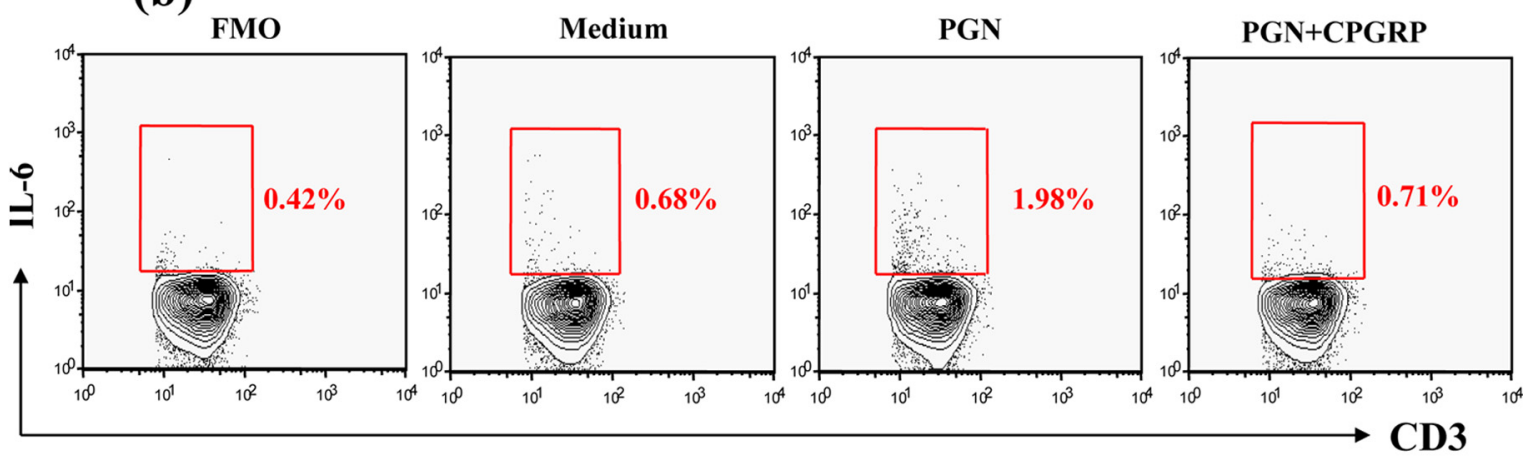

Gated on $\mathrm{CD3}^{+} \mathrm{T}$ cells

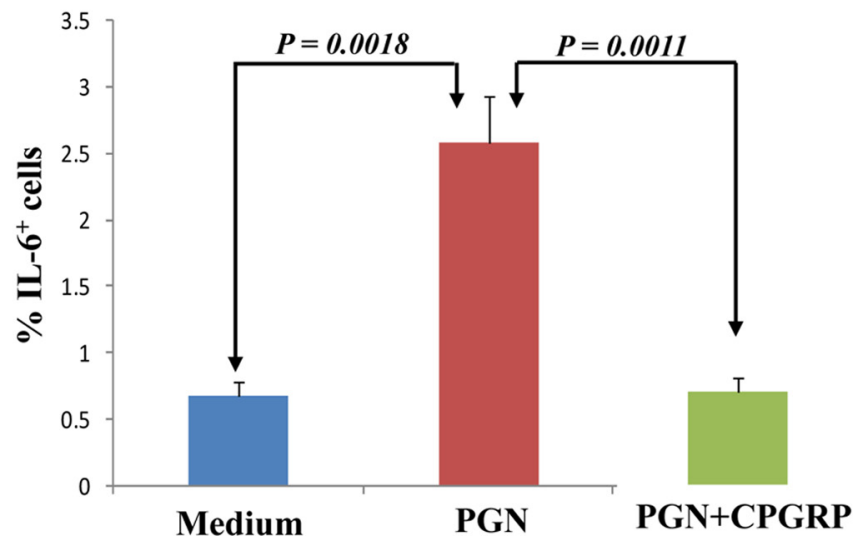




\section{Recognition of Peptidoglycans by CPGRP-S}

and MurNAc. The approximate values of binding constants were found to be of the order $10^{-9} \mathrm{M}$ for PGN and $10^{-7} \mathrm{M}$ for GlcNAc and MurNAc.

CPGRP-S Inhibits PGN-induced Expressions of TNF- $\alpha$ and $I L-6$-The binding studies using surface plasmon resonance and fluorescence spectroscopy showed that CPGRP-S has significantly high binding affinities toward PGN and its chemically important moieties such as GlcNAc and MurNAc. Therefore, it was important to determine whether CPGRP-S is capable of inhibiting the PGN-induced production of proinflammatory cytokines such as TNF- $\alpha$ and IL-6. The production of PGNinduced TNF- $\alpha$ and IL- 6 in human CD3 + T cells was estimated using flow cytometer. It showed $80-90 \%$ inhibition of PGN augmented TNF- $\alpha$ production with $5 \mu \mathrm{g} / \mathrm{ml}$ of CPGRP-S. However, the concentrations higher than $5 \mu \mathrm{g} / \mathrm{ml}$ CPGRP-S did not affect further reduction in TNF- $\alpha$ levels in CD3 $+\mathrm{T}$ cells (supplemental Fig. S4). Therefore, in subsequent experiments $5 \mu \mathrm{g} / \mathrm{ml}$ of CPGRP-S was used as the standard dose for the inhibition of PGN-induced production of TNF- $\alpha$ and IL- 6 . The addition of $10 \mu \mathrm{g} / \mathrm{ml}$ PGN to the cultured cells led to the increase in the expression levels of TNF- $\alpha$ (3.4-fold) and IL-6 (2.7-fold) $24 \mathrm{~h}$ post-treatment. The increased levels of TNF- $\alpha$ and IL- 6 were almost completely abolished ( $>90 \%$ reduction) when the T cells were incubated with $5 \mu \mathrm{g} / \mathrm{ml}$ CPGRP-S along with $10 \mu \mathrm{g} / \mathrm{ml} \mathrm{PGN} \mathrm{(Fig.} \mathrm{4).} \mathrm{This} \mathrm{increase} \mathrm{in} \mathrm{the} \mathrm{levels} \mathrm{of} \mathrm{TNF-} \alpha$ and IL- 6 were comparable to those produced by LPS (4), but these were significantly higher than those produced by LTA (4). However, on the addition of CPGRP-S, the identical reductions were reached. Therefore, these experimental data support the hypothesis that CPGRP-S would attenuate the proinflammatory response of $\mathrm{T}$ cells to PGN in vitro by sequestering PGN, thus making it unavailable to various PAMP receptors such as CD14, TLRs, and CD6 expressed on T cells, known to recognize PAMPs.

Oligomeric Nature of CPGRP-S-Crystal structure determination of CPGRP-S revealed the presence of four crystallographically independent molecules, A, B, C, and D, in the asymmetric unit of the crystal unit cell. The buried surface areas (31, 32) of the interface between molecules $A$ and $B$ was estimated to be $798 \AA^{2}$, and between molecules $C$ and D, it was found to be $702 \AA^{2}$, whereas between molecules $A$ and $C$ it was $\sim 360 \AA^{2}$. The values of buried area between molecules $B$ and $D$ was 111 $\AA^{2}$. These values indicate that the buried areas of molecules A-B and $\mathrm{C}-\mathrm{D}$ fall within the ranges associated with oligomerization of proteins (33) and are considerably larger than those observed between molecules in crystal packings (34). It may also be mentioned that of a total of 13 proline residues in CPGRP-S, nine were located at the interface. It is well known that prolines are frequently found at the interfaces of oligomers (35). The calculations of intermolecular contacts between molecules A and B showed the formations of 13 hydrogen bonds/salt bridges and

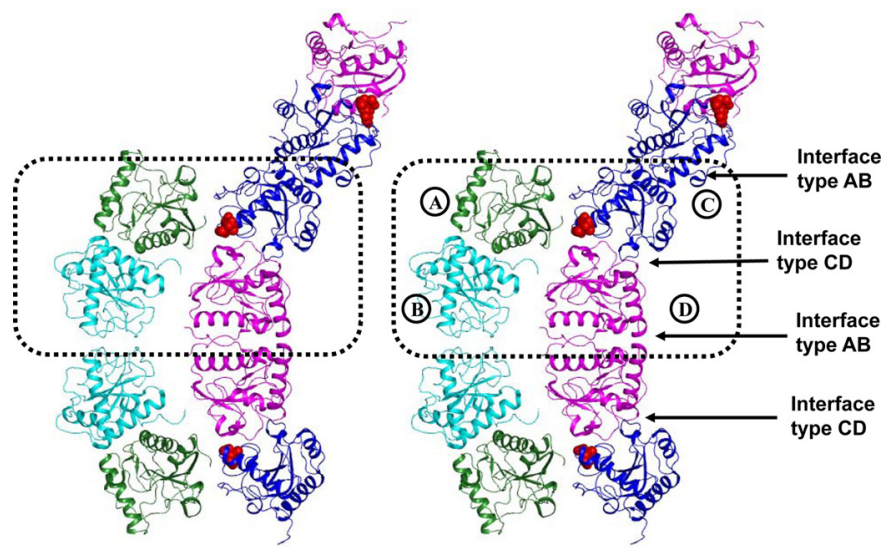

FIGURE 5. Stereo view of the structure of CPGRP-S showing four crystallographically independent molecules in the asymmetric unit, which is indicated by dashed lines. CPGRP-S molecules assemble as linear polymers forming alternating interface types of A-B and C-D. The PAMP binding site is located in molecule $C$ at $C-D$ contacts.

129 van der Waals contacts $(<4.2 \AA)$, whereas between molecules $C$ and $D, 13$ hydrogen bonds and 113 van der Waals contacts $(4.2 \AA)$ were observed. The formations of extensive hydrophobic interactions between protein molecules are considered to be very important for the stability of oligomeric interfaces (36-38). An examination of temperature factors of the residues at the interfaces in the interior and exterior of the protein structure revealed that the average values of $\mathrm{B}$-factor were the lowest in the interiors $\left(43 \AA^{2}\right.$ ) and the highest $\left(58 \AA^{2}\right.$ ) at the exteriors, whereas those at the interfaces were approximately at the middle of these $\left(50 \AA^{2}\right)$. It may be mentioned here that A-B and C-D represent contacts on the opposite faces of CPGRP-S, thus indicating the possibility of CPGRP-S to oligomerize linearly with alternating A-B and C-D contacts (Fig. 5). To confirm the oligomeric state in solution, measurements were made using dynamic light scattering (DLS) and transmission electron microscopy. The hydrodynamic radii as estimated using DLS varied between 59 to $127 \mathrm{~nm}$ (supplemental Table S1). With reduction in protein concentration the values of hydrodynamic radius decreased. It also decreased when $\mathrm{NaCl}$ was added to the protein solution. However, it increased when ethanol was introduced to the protein solution (supplemental Table S1). The transmission electron micrographic pattern also indicated the formation of long protein fibers (supplemental Fig. S5). The repeated size exclusion chromatography experiments always showed a peak in the void volume in spite of adding various concentrations of $\mathrm{NaCl}$ (supplemental Fig. S6).

Structure of Complex of CPGRP-S with GlcNAc-The structure of the complex of CPGRP-S with GlcNAc has been determined at $2.60 \AA$ resolution and refined to $R_{\text {cryst }}$ and $R_{\text {free }}$ factors of 19.6 and $21.4 \%$, respectively. The superimposition of free and

FIGURE 4. The inhibition of PGN-induced cytokine production in human T cells by CPGRP-S. Freshly isolated peripheral blood mononuclear cells derived from peripheral blood of healthy donors were cultured for $24 \mathrm{~h}$ with Golgi bodies transport blocker in the presence and absence of various doses of PGN and CPGRP-S. Cultured cells were washed and surface-stained with anti-CD3 and followed by intracellular staining for TNF- $\alpha$ and IL-6. $a$, a representative FACS plot shows the percentage of TNF- $\alpha$ producing CD3 + T cells under different experimental condition with FMO* controls, and each bar represents the mean \pm S.D. for the measurements from six individual experiments. $b$, a representative FACS plot shows the percentage of IL-6-producing CD3+ T cells under different experimental conditions with FMO controls for IL-6, and each bar represents the mean \pm S.D. for measurements from six individual experiments. FMO, fluorescence minus one. 

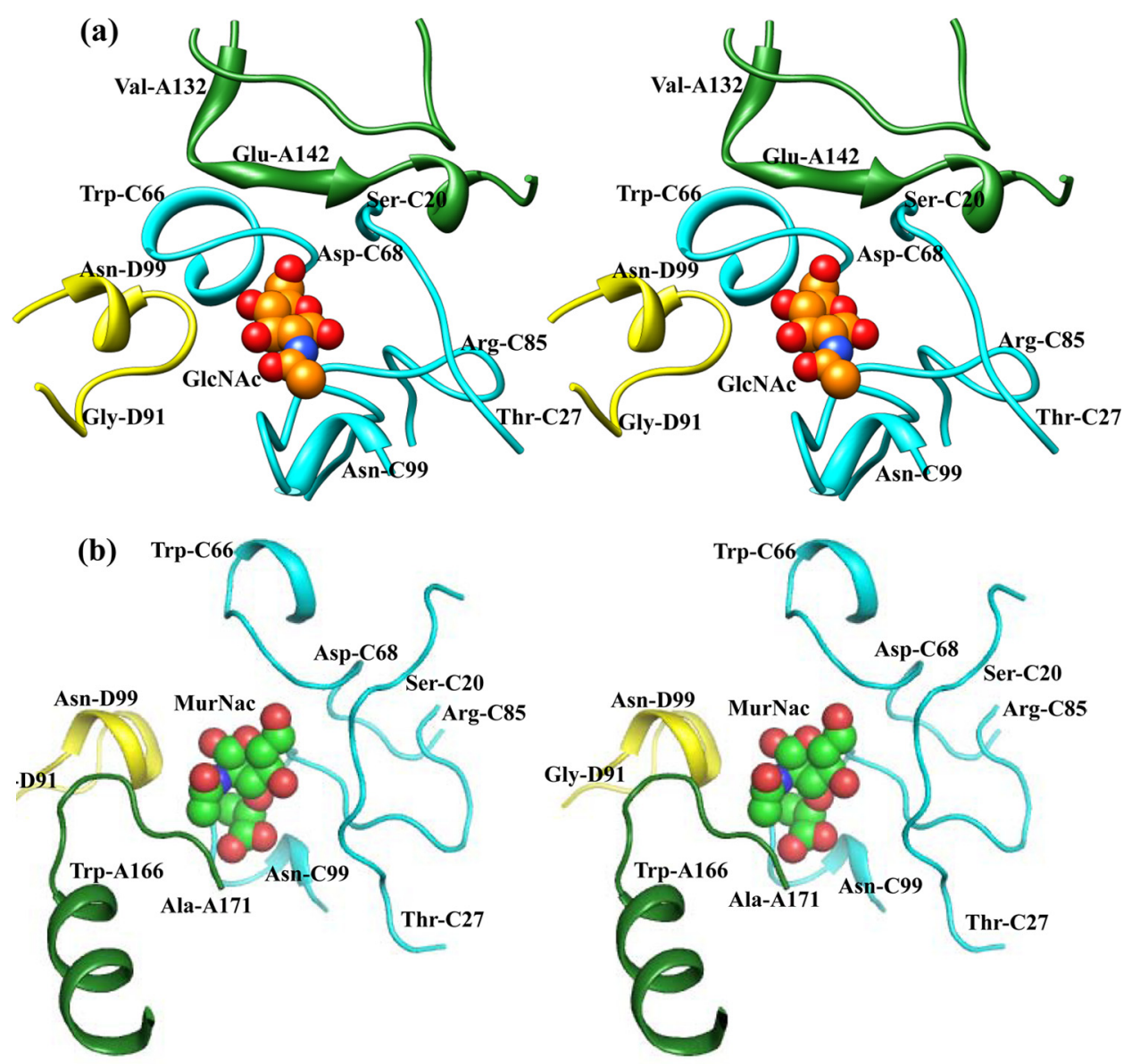

FIGURE 6. $a$, shown are the protein segments from molecules A, C, and D, Val-A132-Glu-A142 (green), Ser-C20-Thr-C27, Trp-C66-Asp-C68, and Arg-C85-AsnC99 (cyan), and Gly-D91-Asn-D99 (yellow) that surround GlcNAc (represented as space fitting model) in the structure. $b$, MurNAc binding subsite is surrounded by protein segments, Trp-A166-Ala-A171 (green), Ser-C20-Thr-C27, Trp-C66-Asp-C68, an dArg-C85-Asn-C99 (cyan), and Gly-D91-Asn-D99 (yellow).

GlcNAc-bound CPGRP-S structures gave a root mean square difference of $0.35 \AA$ for $171 \mathrm{C}^{\alpha}$ atoms, indicating unappreciable conformational variation upon complex formation. However, minor differences were observed in the orientations of side chains of those residues that are in the proximity of the GlcNAc binding subsite. The segments that form the inner walls of the cleft include Val-A132-Glu-A142, Ser-C20Thr-C27, Trp-C66-Asp-C68, Arg-C85-Asn-C99, and GlyD91-Asn-D99 (Fig. 6a). GlcNAc forms five direct hydrogen bonds and five hydrogen bonds through water molecules (Table $2 \mathrm{~A}$ ) and 70 van der Waals contacts $(<4.2 \AA)$ with protein atoms. A notable feature of the GlcNAc binding subsite is the presence of an intramolecular salt bridge between the side chains of Glu-C24 and Lys-C90 belonging to the flexible loops, Glu-1-Arg-31 and Arg-85-Ile-103, which together with Trp-66 form the bottom of the subsite. A similar salt bridge is not formed in HPGRP-S or PGN binding C-terminal HPGRP-I $\alpha$ and HPGRP-I $\beta$ because the Glu- 24 in these proteins is replaced by Gln/Lys/Arg and its partner Lys-90 is replaced by $\mathrm{Thr} / \mathrm{Gln} / \mathrm{Gln}$, respectively.

Structure of Complex of CPGRP-S with MurNAc-The structure of the complex of CPGRP-S with MurNAc has been determined at $2.60 \AA$ resolution and refined to $R_{\text {cryst }}$ and $\mathrm{R}_{\text {free }}$ factors of 22.3 and $24.6 \%$, respectively. The superimposition of free and MurNAc-bound CPGRP-S structures with a root mean square difference of $0.45 \AA$ for $171 \mathrm{C}^{\alpha}$ atoms does not indicate significant conformational variation upon binding of MurNAc. However, the orientations of some of the side chains in the MurNAc binding subsite were altered considerably, prominent among them being Glu-C24 and Lys-C90. MurNAc binds at nearly the same subsite where GlcNAc binds to the protein. The segments that constitute the MurNAc binding subsite are Ser-C20 -ThrC27, Arg-C85-Asn-C99, Trp-C66-Asp-C68, Gly-D91-AsnD99, and Trp-A166-Ala-A171 (Fig. 6b). MurNAc makes 6 direct hydrogen bonds, 1 salt bridge between Lys-C90 NZ. .....O10 $=2.5 \AA$ and 4 hydrogen bonds through water molecules (Table 2B), and 80 van der Waals contacts (up to a distance of $4.2 \AA$ ). In the cases of native structure (27) and other complexes with non-acidic ligands, the side chain of Lys-C90 forms an intramolecular salt bridge with the side chain of GluC24. In contrast, in the complex with MurNAc, the intramolecular salt bridge is broken to facilitate Lys-C90 to form a salt bridge with carboxylic group of MurNAc, whereas Glu-C24 turns away to interact with carboxylic $\mathrm{OH}$ of terminal Ala-171. When it is compared with MDP (5), in which MurNAc moiety occupies the same subsite as occupied by free MurNAc, and GlcNAc, in which MurNAc forms eight direct hydrogen bonds and one is formed through water molecule. The dipeptide moiety forms nine direct hydrogen bonds and four through water molecules. Notably the interactions of MurNAc moiety involve 
TABLE 2

The hydrogen bonded interactions between protein/water and ligand atoms

\begin{tabular}{|c|c|c|c|}
\hline Protein & Water & GlcNAc & Distance \\
\hline & & & $\AA$ \\
\hline Gly-C91 O & & O1 & 3.2 \\
\hline Trp-C66 NE1 & & $\mathrm{O} 4$ & 2.9 \\
\hline Cys-C67 N & & O6 & 3.3 \\
\hline & OW-A233 & O6 & 3.0 \\
\hline Tyr-A32 OH & OW-A233 & & 3.2 \\
\hline Glu-A142 OE1 & OW-A233 & & 2.7 \\
\hline Arg-C85 NH1 & & $\mathrm{O} 5$ & 3.3 \\
\hline & OW-A220 & $\mathrm{O} 5$ & 3.1 \\
\hline Glu-C24 OE1 & OW-A220 & & 2.7 \\
\hline Asn-C99 ND2 & & O7 & 3.2 \\
\hline \multirow[t]{2}{*}{ Protein } & Water & MurNAc & Distance \\
\hline & & & $\AA$ \\
\hline Asn-C99 ND2 & & $\mathrm{O} 3$ & 3.2 \\
\hline Lys-C90 NZ & & $\mathrm{O} 3$ & 3.2 \\
\hline \multirow[t]{2}{*}{ Lys-C90 NZ } & & $\mathrm{O} 4$ & 2.8 \\
\hline & OW-C379 & $\mathrm{O} 5$ & 3.2 \\
\hline Trp-C66 NE1 & OW-C379 & & 3.1 \\
\hline Arg-C85 $\mathrm{NH}_{2}$ & & O6 & 3.2 \\
\hline Arg-A $170 \mathrm{NE}$ & & O7 & 2.9 \\
\hline \multirow[t]{2}{*}{ Lys-C90 NZ } & & $\mathrm{O} 10$ & 2.5 \\
\hline & OW-D386 & $\mathrm{O} 1$ & 2.8 \\
\hline Gln-D150 OE1 & OW-D386 & & 2.5 \\
\hline
\end{tabular}

protein molecules $C$ and D, whereas peptide component essentially interacts with molecule D.

\section{DISCUSSION}

The four crystallographically independent molecules A, B, C, and $D$ observed in the asymmetric unit are represented as A-B and C-D units of two neighboring linear polymers of CPGRP-S. The buried areas as estimated using PISA (39) was slightly higher for the A-B interface than the $C$-D interface, indicating that A-B contact was slightly more stable than the C-D contact. Nevertheless, the buried areas at both the interfaces indicated fairly stable contacts. Hence, the molecules are so arranged in the crystals that they form alternating contacts of types C-D and A-B, giving rise to linear chain of protein molecules (Fig. 5). It may be noted that the PAMP binding site in CPGRP-S is characterized by two subsites (subsites I and II) that are separated by a loop formed between two antiparallel $\beta$-strands $\beta 5$ and $\beta 6$. Both GlcNAc and MurNAc bound to molecule $C$ and were essentially located in subsite I at the C-D contacts (Fig. 5). The binding and structural studies previously carried out with LPS and LTA (4) have clearly shown that the binding site for GlcNAc- and MurNAc-containing PAMPs is located at the site of $\mathrm{C}-\mathrm{D}$ contact. The precise role of A-B contact is not yet clear, although due to proximity to the ligand binding site at the $C-D$ contact, molecule A of A-B of the neighboring unit may provide additional interactions. However, the distant protein molecule $B$ does not interact with short ligands such as GlcNAc and MurNAc and may participate when polymeric PAMPs bind to CPGRP-S at the C-D binding site. It appears that the oligomerization of CPGRP-S occurred to facilitate better interactions with polymeric PAMPs (40). It has been shown that PGRP-S binds to both Lys-type and DAP-type PGNs (41). It is observed here that PGN and two of its glycan moieties, GlcNAc and MurNAc, bind to CPGRP-S with significant affinities as indicated by the values of dissociation constants of $1.3 \times 10^{-9}$, $2.6 \times 10^{-7}$, and $1.8 \times 10^{-7} \mathrm{M}$, respectively. The examination of

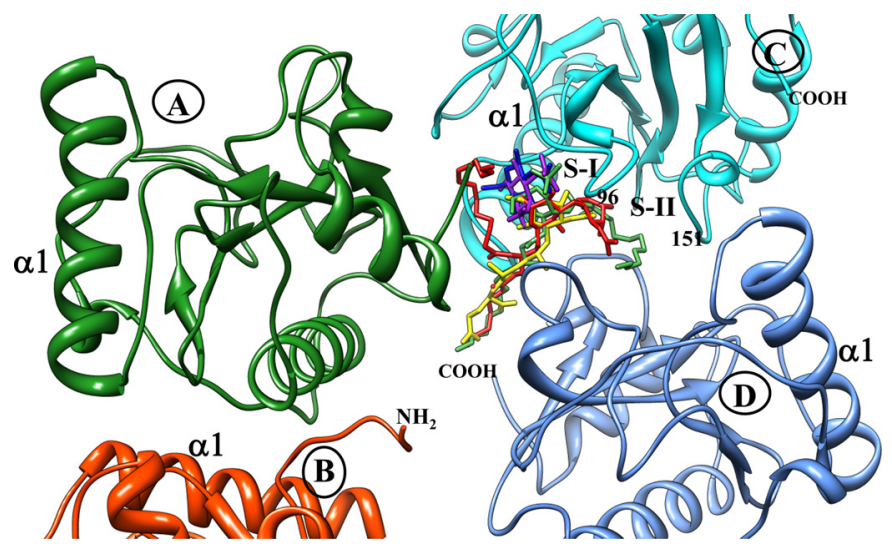

FIGURE 7. Bound molecules of LPS (green), LTA (red), MDP (yellow), GIcNAc (blue), and MurNAc (purple) indicate that the S1 subsite was occupied by glycan moieties, whereas the remaining chemical moieties were adjusted in the other regions of the cleft and along the surface of molecule $D$.

intermolecular interactions between CPGRP-S and GlcNAc and MurNAc showed that both compounds bound to protein tightly as they formed several hydrogen bonds and many van der Waals contacts with protein atoms. GlcNAc made 10 hydrogen bonds and 70 van der Waals interactions with a buried surface area of $260 \AA^{2}$, whereas MurNAc was involved in the formation of 10 hydrogen bonds and 80 van der Waals contacts corresponding to a buried surface area of $290 \AA^{2}$. This showed a slightly higher preference for MurNAc than GlcNAc. The binding of GlcNAc to CPGRP-S did not alter the structure of binding subsite appreciably, whereas that of MurNAc induced notable conformational changes in the binding subsite. In this case an intramolecular linkage formed between the side chains of Glu-C24 and Lys-C90 in the unbound protein was broken due to the interaction of MurNAc with CPGRP-S. As a result, the side chains of Glu-C24 and Lys-C90 moved away considerably from their original positions in the unbound CPGRP-S (27). The conformations of other side chains of some neighboring residues also got perturbed. It is of considerable interest that both the glycan moieties occupied the same pocket in the cleft of molecule C of CPGRP-S. At this subsite, the majority of interactions were provided by molecule $C$ where the pocket is formed, whereas molecules D from the C-D interface and molecule A from the neighboring polymeric chain also contributed several interactions. The excellent fittings of both glycan moieties in the subsite with extensive intermolecular contacts indicated that this subsite is formed optimally for interacting with glycan moieties. The previously determined structures of the complexes of CPGRP-S with other glycan moiety-containing PAMPs such as LPS (4), LTA (4), and muramyl dipeptide (5) showed that their glycan moieties also occupied the same pocket as observed in the present structures, whereas other aliphatic attachments of these molecules were adjusted into other parts of the cleft (Fig. 7). It may be noted here that PAMPs such as LPS and LTA do not contain peptide components. On the other hand, in human PGRPs, PGRP-I $\alpha \mathrm{C}$ (7), and PGRP$\mathrm{I} \beta C$ (8), it was reported that the glycan moieties were held in subsite II, whereas the peptide components were placed parallel to subsite I (Fig. 8a). In this arrangement the peptide component made more interactions with protein atoms than the gly- 


\section{Recognition of Peptidoglycans by CPGRP-S}

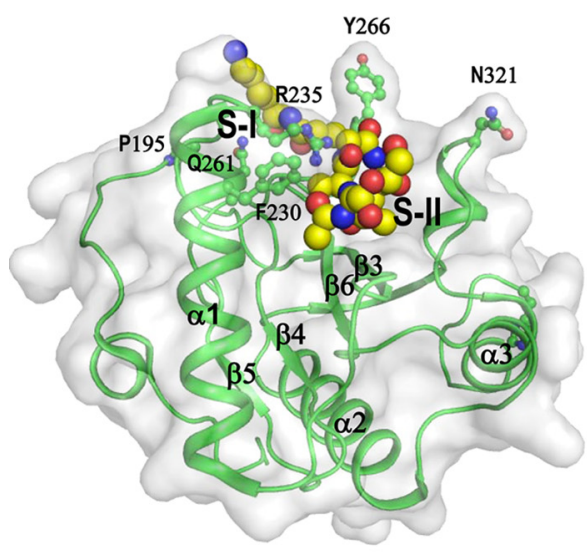

(a)

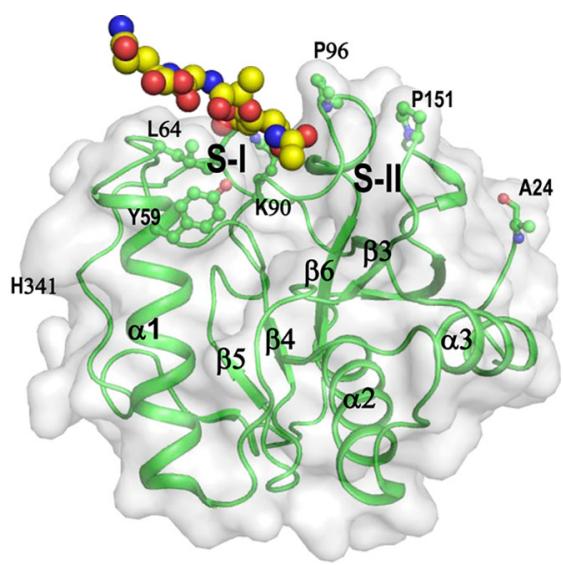

(b)

FIGURE 8. $a$, shown is a schematic and surface display of the binding of MTP to HPGRP-1 $\alpha$ C (PDB ID 1TWQ), where glycan moiety is bound in subsite II (S-II), whereas peptide is adjusted along S-I. The inner part of subsite S-I is empty. $b$, a schematic and surface display of CPGRP-S is shown. Secondary structure elements are labeled. The residues of the binding site are indicated. Two subsites, S-I and S-II, are labeled. Binding of MDP to CPGRP-S is shown where glycan moiety is placed in subsite S-I and peptide moiety is aligned along the surface of molecule $D$, whereas subsite $S$-II is empty because of constraints from molecule $D$.

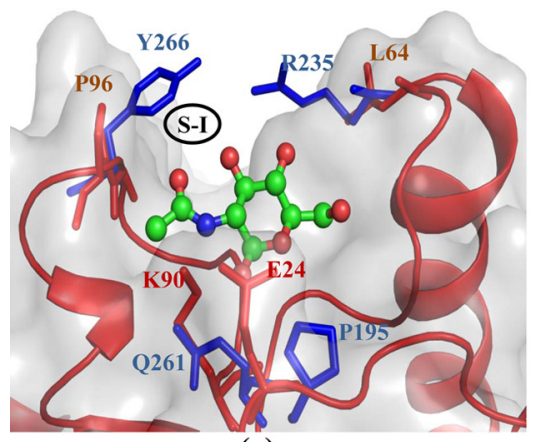

(a)

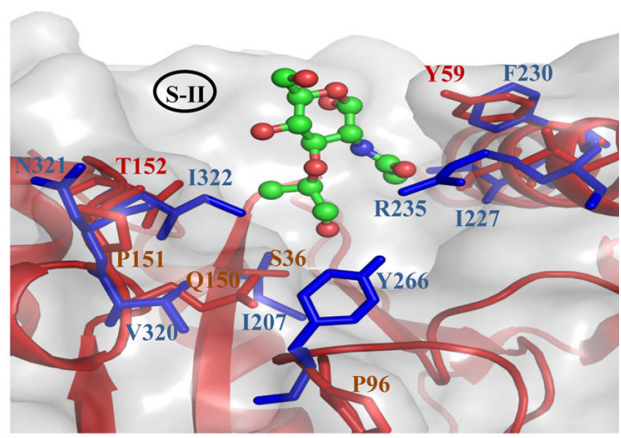

(b)

FIGURE 9. The comparison of glycan bindings in subsite I of CPGRP-S (PDB ID 3NW3) (a) and subsite II (b) of HPGRP-I $\alpha$ C (PDB ID 1TWQ). The residues in red represent CPGRP-S, whereas those of HPGRP-I $\alpha$ C are shown in blue. As seen from $a$, subsite I is narrower in HPGRP-I $\alpha$ C than CPGRP-S, whereas the residues in subsite II of HPGRP-I $\alpha$ C are favorable for the binding to glycan moieties.

can moieties, indicating it to be a more preferred moiety of MTP for the interactions with protein atoms (35). In this structure MTP formed 9 hydrogen bonds and 138 van der Waals contacts, and the buried area was estimated to be $182 \AA^{2}$. The comparable structure of CPGRP-S with MDP showed that the glycan moiety was placed in subsite I in molecule $\mathrm{C}$, whereas the peptide position was held through the interactions with molecule D of the same polymeric chain and molecule $\mathrm{A}$ of the neighboring polymeric chain (Fig. 8b). In this case, MDP made 14 hydrogen bonds and 134 van der Waals interactions with a buried surface area of $232 \AA^{2}$. Although the size of MDP is smaller than MTP, it formed larger number of interactions with protein atoms as compared with MTP. This clearly showed that the binding of MDP to CPGRP-S was stronger than that of MTP to HPGRP-I $\alpha \mathrm{C}$ (7) and HPGRP-I $\beta C$ (8). A further comparison of the structure of CPGRP-S complex with MDP (PDB ID $3 N W 3$ ) with that of HPGRP-I $\alpha$ C (PDB ID 1TWQ) revealed that the subsites I and II are formed slightly differently because the mode of binding of MDP in CPGRP-S and MTP in HPGRP$\mathrm{I} \alpha \mathrm{C}$ (Fig. 9, $a$ and $b$ ) differ considerably. The examination of subsite I in CPGRP-S shows that the separation between the nearest atoms of residues Leu-64 and Pro-151 from opposite sides of the opening to the subsite I is $15.3 \AA$ (Fig. 9a), whereas the corresponding minimum distance between the correspond- ing residues Arg-235 and Tyr-266 in HPGRP-I $\alpha$ C is $4.9 \AA$, indicating it to be too narrow to allow the entry of the glycan moiety. On the other hand, the structure of subsite II in HPGRP- $\mathrm{I} \alpha \mathrm{C}$ is more favorable for the binding of glycan moieties because of several favorable interactions that are provided by residues Ile-207, Phe-230, Arg-235, Tyr-242, and Ile-322 (Fig. 9b). The corresponding residues in CPGRP-S are Ser-36, Tyr-59, Leu-64, Tyr-71, and Thr-152, which are slightly less favorable. The binding properties might also have been influenced by a unique polymeric arrangement of protein molecules in CPGRP-S. The corresponding structural data are not available on the human PGRP-S where the crystal structure of only a truncated HPGRP-S containing residues from 9 to 175 as a monomer has been reported so far (18). The PAMP binding sites in the domains DPGRP-LCx (9) and DPGRP-LCa (9), similar to that of PGRP-S, show considerable differences with that of CPGRP-S as a result of which an accurate comparison is not possible. Therefore, in the case of CPGRP-S, it appears that glycan moieties play a more important role in the recognition than the peptide moieties, whereas in human PGRP-I $\alpha \mathrm{C}$ and PGRP-I $\beta C$, peptide moieties were presumed to be more crucial for the recognition. This difference in the preference could also be related to the state of quaternary structures of these proteins. Because subsite II is slightly constrained in CPGRP-S due to a loop 


\section{Recognition of Peptidoglycans by CPGRP-S}

from molecule $\mathrm{D}$ of the polymeric chain, it is unfavorable for interactions with other molecules. On the other hand, the binding in subsite I is favored due to the possibility of additional interactions from molecules $\mathrm{A}$ of the neighboring chain and molecule D of the same chain. These observations indicated that the mode of binding of PAMPs in CPGRP-S is better than in human PGRP-I $\alpha$ C and PGRP-I $\beta$ C. It may also be mentioned here that the conserved parts of various PAMPs are their two glycan moieties, GlcNAc and MurNAc, whereas the sequences of cross-linking peptides vary in amino acid sequences, lengths, and flexibilities as well as the cross-linking peptides in the structure of PGN are poorly accessible. Therefore, the preferable element of recognition in PGN and other glycan containing PAMPs may be their glycan moieties. It is likely that the PAMPs lacking in glycan components may bind to CPGRP-S poorly.

\section{REFERENCES}

1. Liu, C., Gelius, E., Liu, G., Steiner, H., and Dziarski, R. (2000) Mammalian peptidoglycan recognition protein binds peptidoglycan with high affinity, is expressed in neutrophils, and inhibits bacterial growth. J. Biol. Chem. 275, 24490-24499

2. Janeway, C. A., Jr. (1989) Cold Spring Harbor Symp. Quant. Biol. 54, 1-13

3. Schleifer, K. H., and Stackebrandt, E. (1983) Molecular systematics of prokaryotes. Annu. Rev. Microbiol. 37, 143-187

4. Sharma, P., Dube, D., Singh, A., Mishra, B., Singh, N., Sinha, M., Dey, S., Kaur, P., Mitra, D. K., Sharma, S., and Singh, T. P. (2011) Structural basis of recognition of pathogen-associated molecular patterns and inhibition of proinflammatory cytokines by camel peptidoglycan recognition protein. J. Biol. Chem. 286, 16208-16217

5. Sharma, P., Dube, D., Sinha, M., Mishra, B., Dey, S., Mal, G., Pathak, K. M., Kaur, P., Sharma, S., and Singh, T. P. (2011) Multiligand specificity of pathogen-associated molecular pattern binding site in peptidoglycan recognition protein. J. Biol. Chem. 286, 31723-31730

6. Mellroth, P., Karlsson, J., and Steiner, H. (2003) A scavenger function for a Drosophila peptidoglycan recognition protein. J. Biol. Chem. 278, 7059-7064

7. Guan, R., Brown, P. H., Swaminathan, C. P., Roychowdhury, A., Boons, G. J., and Mariuzza, R. A. (2006) Crystal structure of human peptidoglycan recognition protein $\mathrm{I} \alpha$ bound to a muramyl pentapeptide from Grampositive bacteria. Protein Sci. 15, 1199-1206

8. Cho, S., Wang, Q., Swaminathan, C. P., Hesek, D., Lee, M., Boons, G. J., Mobashery, S., and Mariuzza, R. A. (2007) Structural insights into the bactericidal mechanism of human peptidoglycan recognition proteins. Proc. Natl. Acad. Sci. U.S.A. 104, 8761-8766

9. Chang, C. I., Chelliah, Y., Borek, D., Mengin-Lecreulx, D., and Deisenhofer, J. (2006) Structure of tracheal cytotoxin in complex with a heterodimeric pattern-recognition receptor. Science 311, 1761-1764.

10. Dziarski, R. A., Ulmer, and Gupta, D. (2000) in Glycomicrobiology (Doyle, R. J., ed.) pp. 145-186, Kluwer Academic/Plenum Publishers

11. Doyle, R., and Dziarski, R. (2001) in Molecular Medical Microbiology (Sussman, M., ed.) pp. 137-154, Academic Press, Inc., New York

12. De Kimpe, S. J., Kengatharan, M., Thiemermann, C., and Vane, J. R. (1995) The cell wall components peptidoglycan and lipoteichoic acid from Staphylococcus aureus act in synergy to cause shock and multiple organ failure. Proc. Natl. Acad. Sci. U.S.A. 92, 10359-10363

13. Hoffmann, J. A. (2003) The immune response of Drosophila. Nature 426, 33-38

14. Dziarski, R. (2004) Peptidoglycan recognition proteins (PGRPs). Mol. Immunol. 40, 877-886

15. Kang, D., Liu, G., Lundström, A., Gelius, E., and Steiner, H. (1998) A peptidoglycan recognition protein in innate immunity conserved from insects to humans. Proc. Natl. Acad. Sci. U.S.A. 95, 10078-10082

16. Ochiai, M., and Ashida, M. (1999) A pattern recognition protein for peptidoglycan. Cloning the cDNA and the gene of the silkworm, Bombyx mori. J. Biol. Chem. 274, 11854-11858

17. Werner, T., Liu, G., Kang, D., Ekengren, S., Steiner, H., and Hultmark, D. (2000) A family of peptidoglycan recognition proteins in the fruit fly Drosophila melanogaster. Proc. Natl. Acad. Sci. U.S.A. 97, 13772-13777

18. Guan, R., Wang, Q., Sundberg, E. J., and Mariuzza, R. A. (2005) Crystal structure of human peptidoglycan recognition protein S (PGRP-S) at 1.70 Å resolution. J. Mol. Biol. 347, 683-691

19. Liu, C., Xu, Z., Gupta, D., and Dziarski, R. (2001) Peptidoglycan recognition proteins. A novel family of four human innate immunity pattern recognition molecules. J. Biol. Chem. 276, 34686-34694

20. Kappeler, S. R., Heuberger, C., Farah, Z., and Puhan, Z. (2004) Expression of the peptidoglycan recognition protein, PGRP, in the lactating mammary gland. J. Dairy Sci. 87, 2660-2668

21. Guan, R., Roychowdhury, A., Ember, B., Kumar, S., Boons, G. J., and Mariuzza, R. A. (2004) Structural basis for peptidoglycan binding by peptidoglycan recognition proteins. Proc. Natl. Acad. Sci. U.S.A. 101, $17168-17173$

22. Takehana, A., Katsuyama, T., Yano, T., Oshima, Y., Takada, H., Aigaki, T., and Kurata, S. (2002) Overexpression of a pattern-recognition receptor, peptidoglycan-recognition protein-LE, activates imd/relish-mediated antibacterial defense and the prophenoloxidase cascade in Drosophila larvae. Proc. Natl. Acad. Sci. U.S.A. 99, 13705-13710

23. Reissig, J. L., Storminger, J. L., and Leloir, L. F. (1955) A modified colorimetric method for the estimation of $\mathrm{N}$-acetylamino sugars. J. Biol. Chem. 217, 959-966

24. Hoijer, M. A., Melief, M. J., van Helden-Meeuwsen, C. G., Eulderink, F., and Hazenberg, M. P. (1995) Detection of muramic acid in a carbohydrate fraction of human spleen. Infect Immun. 63, 1652-1657

25. Otwinowski, Z., and Minor, W. (1996) Methods Enzymol. 276, 307-326

26. Evans, P., and McCoy, A. (2008) Acta Crystallogr. D Biol. Crystallogr 64, $1-10$

27. Sharma, P., Singh, N., Sinha, M., Sharma, S., Perbandt, M., Betzel, C., Kaur, P., Srinivasan, A., and Singh, T. P. (2008) Crystal structure of the peptidoglycan recognition protein at $1.8 \AA$ resolution reveals dual strategy to combat infection through two independent functional homodimers. $J$. Mol. Biol. 378, 923-932

28. Jones, T. A., Zou, J. Y., Cowan, S. W., and Kjeldgaard, M. (1991) Improved methods for building protein models in electron density maps and the location of errors in these models. Acta Crystallogr. A 47, 110-119

29. Emsley, P., and Cowtan, K. (2004) Coot. Model-building tools for molecular graphics. Acta Crystallogr. D Biol. Crystallogr 60, 2126-2132

30. Murshudov, G. N., Vagin, A. A., and Dodson, E. J. (1997) Refinement of macromolecular structures by the maximum-likelihood method. Acta Crystallogr. D Biol. Crystallogr 53, $240-255$

31. Brünger, A. T., Adams, P. D., Clore, G. M., DeLano, W. L., Gros, P., Grosse-Kunstleve, R. W., Jiang, J. S., Kuszewski, J., Nilges, M., Pannu, N. S., Read, R. J., Rice, L. M., Simonson, T., and Warren, G. L. (1998) Crystallography and NMR system. A new software suite for macromolecular structure determination. Acta Crystallogr. D Biol. Crystallogr 54, 905-921

32. Lee, B., and Richards, F. M. (1971) The interpretation of protein structures. Estimation of static accessibility. J. Mol. Biol. 55, 379-4.00

33. Larson, S. B., Day, J. S., Nguyen, C., Cudney, R., and McPherson, A. (2010) Structure of a crystal form of human methemoglobin indicative of fiber formation. Acta Crystallogr. D Biol. Crystallogr. 66, 1316-1322

34. Dasgupta, S., Iyer, G. H., Bryant, S. H., Lawrence, C. E., and Bell, J. A. (1997) Extent and nature of contacts between protein molecules in crystal lattices and between subunits of protein oligomers. Proteins 28, 494-514

35. Tsai, C. J., Lin, S. L., Wolfson, H. J., and Nussinov, R. (1997) Studies of protein-protein interfaces. A statistical analysis of the hydrophobic effect. Protein Sci. 6, 53-64

36. Janin, J., Miller, S., and Chothia, C. (1988) Surface, subunit interfaces and interior of oligomeric proteins. J. Mol. Biol. 204, 155-164.

37. Argos, P. (1988) An investigation of protein subunit and domain interfaces. Protein Eng. 2, 101-113

38. Jones, S., and Thornton, J. M. (1995) Protein-protein interactions. A review of protein dimer structures. Prog. Biophys. Mol. Biol. 63, 31-65 


\section{Recognition of Peptidoglycans by CPGRP-S}

39. Krissinel, E., and Henrick, K. (2007) Inference of macromolecular assemblies from crystalline state. J. Mol. Biol. 372, 774-797

40. Swaminathan, C. P., Brown, P. H., Roychowdhury, A., Wang, Q., Guan, R., Silverman, N., Goldman, W. E., Boons, G. J., and Mariuzza, R. A. (2006) Dual strategies for peptidoglycan discrimination by peptidoglycan recognition proteins (PGRPs). Proc. Natl. Acad. Sci. U.S.A. 103,
$684-689$

41. Kumar, S., Roychowdhury, A., Ember, B., Wang, Q., Guan, R., Mariuzza, R. A., and Boons, G. J. (2005) Selective recognition of synthetic lysine and meso-diaminopimelic acid-type peptidoglycan fragments by human peptidoglycan recognition proteins I $\alpha$ and S. J. Biol. Chem. 280, 37005-37012 